\title{
Influence of Light, Relative Humidity, and Maturity of Populations on Discharge of Ascospores of Venturia inaequalis
}

\author{
David M. Gadoury, Arne Stensvand, and Robert C. Seem
}

First and third authors: Department of Plant Pathology, Cornell University, New York State Agricultural Experiment Station, Geneva 14456; and second author: Department of Plant Pathology, Plant Protection Centre, Norwegian Crop Research Institute, Fellesbygget 1432 Ås, Norway. Accepted for publication 4 June 1998.

\begin{abstract}
Gadoury, D. M., Stensvand, A., and Seem, R. C. 1998. Influence of light, relative humidity, and maturity of populations on discharge of ascospores of Venturia inaequalis. Phytopathology 88:902-909.

Ascospore release in 20 populations of Venturia inaequalis was generally suppressed in wind tunnel tests during darkness and simulated rain, but the following relieved this suppression: (i) exposure to low relative humidity during simulated rain and (ii) protracted incubation of leaf samples and the consequent senescence of the pathogen population. No counterpart to (i) was observed under orchard conditions. Although $V$. inaequalis also released a high percentage of ascospores during darkness in field studies under simulated rain late in the season of ascospore re-

stimulatory light intensity. Ascospore release increased with increasing light intensity from 0.5 to $5.2 \mu \mathrm{W} / \mathrm{cm}^{2}$ at $725 \mathrm{~nm}$. There was also an intrinsic increase in ascospore release as duration of rain increased. In orchards, the combined impact of both processes is probably responsible for a delay in reaching peak ascospore release at several hours after sunrise. Ascospore release during darkness will generally constitute a small proportion of the total available supply of primary inoculum. Significant ascospore release, and therefore infection periods, can be assumed to begin shortly after sunrise, when rain begins at night in orchards with low potential ascospore dose (PAD). A PAD level of 1,000 ascospores per $\mathrm{m}^{2}$ of orchard floor per season is suggested as a threshold, above which the night-released ascospores should not be ignored.
\end{abstract} lease, this phenomenon has not been reported for natural rain events. A threshold value of $0.5 \mu \mathrm{W} / \mathrm{cm}^{2}$ at $725 \mathrm{~nm}$ was identified as the minimum
Additional keywords: aerobiology, epidemiology, infection periods.
Venturia inaequalis (Cooke) G. Wint. forms pseudothecial initials within the internal tissues of infected apple leaves shortly after leaf abscission (1). A locule forms within the pseudothecium during overwintering, and the bitunicate asci that are characteristic of the subclass Loculoascomycetidae form shortly thereafter. The bitunicate ascus is composed of a relatively thick-walled, rigid exoascus and a thin-walled, extensible endoascus. When the leaf tissue bearing the pseudothecium is wetted, water moves into the ascocarp either through the ostiole or through the porous ascocarp wall and then into the asci through osmosis (2). Physiologically mature asci (12) then swell and protrude through the ostiole. If the exoascus tip ruptures, the endoascus extends farther, until the entire structure is approximately twice its original length, and protrudes approximately $40 \mu \mathrm{m}$ beyond the ostiole (5). Following the rupture of the endoascus tip, the uppermost spore is forcibly ejected $(19,32)$. Each successive spore within the ascus is discharged after pausing briefly at the ascus tip. The osmotic nature of the mechanism of ascospore discharge results in a slowing of the process at low temperatures, presumably through effects on membrane permeability and biochemical processes (31).

The movement of the ascus from within a closed, protective, and opaque ascocarp into the atmosphere nearly $40 \mu \mathrm{m}$ above the leaf surface is a significant feature of the process of ascospore release in $V$. inaequalis and creates an opportunity for several interactions between the ascus and the external environment. Light, specifically far-red light from 710 to $730 \mathrm{~nm}$ (6), is known to affect ascospore discharge in $V$. inaequalis $(3-5,8,9,18,21,27)$ and at least five other fungi with bitunicate asci $(7,8)$. The suppression of asco-

Corresponding author: D. M. Gadoury; E-mail address: dmg4@ cornell.edu

Publication no. P-1998-0717-01R

(C) 1998 The American Phytopathological Society spore release during darkness is not absolute. During 31 continuous rain and leaf-wetness events over a 4-year period, MacHardy and Gadoury (21) trapped from 91 to $100 \%$ of all ascospores between 0700 and $1800 \mathrm{~h}$ standard time (ST). Aylor and Sutton (3) reported a similar degree of suppression during darkness during 19 of 20 events during which rainfall was intermittent. Warner and Braun (33) trapped 87\% of the season's ascospores between 0500 and $2000 \mathrm{~h} \mathrm{ST}$ (the times of sunrise and sunset at the research site in Ontario, Canada, during the season of ascospore release).

MacHardy and Gadoury (22) have revised Mills' (25) criteria for predicting apple scab infection periods to reflect the low proportion of ascospores released during darkness and recommended the revised criteria for orchards with low potential ascospore dose (PAD) $(11,20)$. Warner and Braun (33) suggested that the 0700 to $1800 \mathrm{~h}$ daytime interval described by MacHardy and Gadoury (22) be extended to 0500 to $2000 \mathrm{~h}$ for eastern Canada.

In several unpublished and at least two published reports $(17,33)$, the pattern of diurnal periodicity of ascospore release and the suppression of ascospore release by darkness has not been consistently reproduced in the laboratory. Thus, while field experiments have been remarkably consistent both worldwide and over a period of several decades, laboratory experiments were less comprehensive, and results were often inconsistent with field observations. The consequent uncertainty has, in some cases, delayed the adoption of revised criteria for predicting apple scab infection periods. Recently, we developed a wind tunnel for controlled environment studies of ascospore release by $V$. inaequalis $(13,15,16)$, used this apparatus to produce realistic simulations of orchard rain events in the laboratory, and thereby consistently reproduced the normal suppression of ascospore release by darkness (16). In this paper, we report further investigations using this apparatus to determine the effects of light, relative humidity $(\mathrm{RH})$, and maturity of populations on discharge of ascospores of $V$. inaequalis. We further report on 
parallel field studies of ascospore release under simulated rain and the pattern of ascospore release in an international collection of 20 populations of $V$. inaequalis. Preliminary accounts of this work have been published elsewhere $(13,15)$.

\section{MATERIALS AND METHODS}

Brief description of wind tunnel used in laboratory studies. We used a bench-top wind tunnel for the study of ascospore release by $V$. inaequalis in controlled environments (16). Compressed air was forced through a column of water to adjust RH. Air then entered one end of a 102-mm-diameter tube at the rate of 20 liters/ min, passed over a platform holding a leaf sample bearing pseudothecia of $V$. inaequalis, and exited the tunnel through a 2- by $10-\mathrm{mm}$ orifice $20 \mathrm{~cm}$ downwind of the sample. Ascospores exiting the orifice impacted on a clear plastic tape borne on a clock cylinder that revolved once in 6,12 , or $24 \mathrm{~h}$. Temperature of the leaf sample was monitored by a thermocouple embedded in the sample platform and recorded by a datalogger. Light was directed to the leaf sample through a fiber-optic bundle coupled to a $150-\mathrm{W}$ quartzhalogen lamp. The quality and intensity of the light was adjusted by colored or neutral density filters at the source. Simulated rain was applied to the leaf sample at the rate of $5.3 \mathrm{~cm} / \mathrm{h}$ through a fine-spray nozzle located $50 \mathrm{~cm}$ above the sample. The temperature of the simulated rain, as well as a water jacket surrounding the tunnel, was controlled by passing the water supply through a controlled-temperature bath.

Ascospores collected on the clear plastic tape were enumerated by mounting sections of the tape on microscope slides in lactoglycerol and scanning the tape at right angles to the direction of rotation as described by Gadoury et al. (16). Tapes were scanned at a magnification of 320 to 800 at 2-mm intervals, which corresponded to 2.47-, 4.95-, and 9.90-min intervals at 6-, 12-, and 24-h rotations, respectively (16). The number of ascospores counted in each transect was adjusted for the magnification used, but not for trap efficiency, and cumulative ascospore release was calculated from the summation of ascospores counted in each transect.

Collection and storage of populations of $\boldsymbol{V}$. inaequalis and preparation of samples for wind tunnel studies. Leaves were collected beneath heavily scabbed trees between the fruit bud phenophases of green tip and petal fall. The leaves were then air-dried, and those collected outside of Geneva, NY, were shipped via air to our lab and frozen upon arrival at $-15^{\circ} \mathrm{C}$ until needed (Table 1).
Disks (1-cm diameter) were cut from each leaf collection. Twenty of these disks were arranged in a 4 by 5 array on the sample platform of the wind tunnel, which was a 5 - by $5-\mathrm{cm}$ piece of closedcell polyurethane foam. The disks were secured to the foam pad with stainless steel pins. The disks borne upon one foam pad represented a single replication of a treatment for subsequent tests involving the wind tunnel, as previously described (16).

Effect of low RH on the suppression of ascospore release by darkness. Leaf disks from Alnarp, Sweden, or Geneva, NY (sites 17 and 67, respectively) (Table 1), were loaded onto the sample platform of the wind tunnel at $1600 \mathrm{~h}$. Until $0800 \mathrm{~h}$ the following morning, the interior temperature was maintained at $20^{\circ} \mathrm{C}$, and humidified air (90 to $94 \% \mathrm{RH}$ ) was circulated through the tunnel at 20 liters/min. Thereafter, the leaf disks were subjected to continuous simulated rain for $6 \mathrm{~h}$. The leaf disks were in complete darkness for the first $3 \mathrm{~h}$ of this period and were illuminated during the latter half of the period. The intensity and quality of light provided approximated that reported earlier for rain events during May at Geneva, NY (16). The RH of the air entering the tunnel was either maintained at 90 to $94 \%$ or was reduced to 10 to $15 \%$ coincident with the onset of simulated rain. Each treatment (humid air versus dry air during rain) was replicated three times for each leaf collection.

Effects of light quality and intensity on ascospore release. The intensity and quality of light supplied to leaf samples within the wind tunnel could be adjusted by means of previously described daylight-balanced and neutral density filters (16). Colored filters yielding peak transmittance in the violet or red portions of the visible spectrum (Fig. 1) were employed to isolate the wavelengths responsible for the stimulation of ascospore release. Leaf samples collected at site 67 (Table 1) were prepared as described above and placed in the wind tunnel at $1600 \mathrm{~h}$. The samples were kept in complete darkness at $20^{\circ} \mathrm{C}$, and humidified air (90 to $94 \% \mathrm{RH}$ ) was circulated through the tunnel overnight. At $0800 \mathrm{~h}$ the following morning, simulated rain was applied to the leaf samples, while $\mathrm{RH}$ was maintained at 90 to $94 \%$. After $2 \mathrm{~h}$ of simulated rain in darkness, the leaf samples were exposed to light with either the violet or red filter in place for an additional $4 \mathrm{~h}$. Neutral density filter numbers 0.1 and 0.6 (transmittance of 80 and $25 \%$, respectively) were used in combination with the red filter to reduce peak intensity to approximate a level observed in natural sunlight (Fig. 1) during rain (16). Positive and negative controls, respectively, consisted of (i) illumination of the sample with a daylight-balanced

TABLE 1. Description of populations of Venturia inaequalis and the percentage of ascospores released during darkness when subjected to simulated rain in a wind tunnel

\begin{tabular}{llllr}
\hline Population number & \multicolumn{1}{c}{ Site of collection } & Cultivar & Tree phenology at collection & Ascospore release during darkness $(\%)^{\mathrm{a}}$ \\
\hline 1 & Bologna, Italy & Delicious & Bloom & $67.8 \pm 8.1$ \\
3 & Corvallis, OR & Delicious & Petal fall & $16.0 \pm 2.9$ \\
4 & Waynesville, NC & Golden Delicious & Bloom & $48.5 \pm 10.6$ \\
6 & Pikis, Finland & Lobo & Green tip & $7.5 \pm 0.7$ \\
13 & Ås, Norway & Summerred & Green tip & $7.1 \pm 1.6$ \\
15 & Årslev, Denmark & Delicious & Green tip & $4.1 \pm 0.3$ \\
16 & Alnarp, Sweden & John Downie & Green tip & $1.4 \pm 0.2$ \\
17 & Alnarp, Sweden & John Downie & Green tip & $2.3 \pm 0.4$ \\
19 & Njös, Norway & Vista Bella & Green tip & $4.4 \pm 2.2$ \\
28 & Friedrichshafen, Germany & Gravenstein & Pink & $12.2 \pm 1.1$ \\
32 & Trenton, Ontario, Canada & McIntosh & Pink & $19.1 \pm 3.7$ \\
33 & Vineland, Ontario, Canada & McIntosh & Bloom & $79.5 \pm 3.9$ \\
36 & Sturgeon Bay, WI & Baldwin & Petal fall & $61.1 \pm 9.5$ \\
50 & Lenswood, SA, Australia & Granny Smith & Tight cluster & $14.8 \pm 0.2$ \\
53 & Hood River, OR & Rome Beauty & Green tip & $3.0 \pm 0.1$ \\
56 & Ås, Norway & Gobo & Green tip & $2.1 \pm 0.1$ \\
60 & Highland, NY & McIntosh & Green tip & $3.0 \pm 0.2$ \\
67 & Geneva, NY & McIntosh & Green tip & $3.2 \pm 0.3$ \\
68 & Geneva, NY & McIntosh & Pink & $13.5 \pm 1.5$ \\
69 & Geneva, NY & McIntosh & 1 cm green & $7.9 \pm 1.1$ \\
\hline
\end{tabular}

${ }^{a}$ Phenology of apple fruit buds at the time of collection at the collection site. Leaf samples from outside Geneva, NY, were air-dried, shipped via air to Geneva, and frozen upon arrival at $-15^{\circ} \mathrm{C}$.

b Twenty 1-cm disks bearing pseudothecia were subjected to $3 \mathrm{~h}$ of simulated rain during darkness, followed by $3 \mathrm{~h}$ of simulated rain and daylight-balanced illumination. The mean and standard error of the cumulative percentage of ascospores released during darkness for three repetitions of the experiment are reported. 
filter in place during hours 3 to 6 and (ii) continued darkness during the above interval. All samples were exposed to daylight-balanced illumination after $6 \mathrm{~h}$ for an additional $3 \mathrm{~h}$ to harvest all available ascospores. Stimulation of ascospore discharge by wavebands transmitted by the violet or red filters was assumed if the percentage of total release during hours 3 to 6 was significantly greater than the negative control (Students $t$ test, $\alpha=0.05$ ). The magnitude of stimulation of a waveband was inferred by comparison of ascospore release during hours 3 to 6 to the positive control. Treatments were replicated three times, and the experiment was repeated using leaf samples from site 17 (Table 1).

To determine the effect of light intensity upon the rate of ascospore discharge, we exposed leaf samples from site 67 (Table 1) to simulated rain in complete darkness for $2 \mathrm{~h}$, followed by illumination for $2 \mathrm{~h}$ at $0.25,2.5$, or $5.2 \mu \mathrm{W} / \mathrm{cm}^{2}$ at $725 \mathrm{~nm}$. These levels correspond to intensity of $725 \mathrm{~nm}$ measured during rain at 0500 , 0630, and $0720 \mathrm{~h}$ EST on 24 May at Geneva, NY, in a previous study (16). Controls were maintained in darkness during hours 3 and 4. All samples were then exposed to an additional $5 \mathrm{~h}$ of illumina-
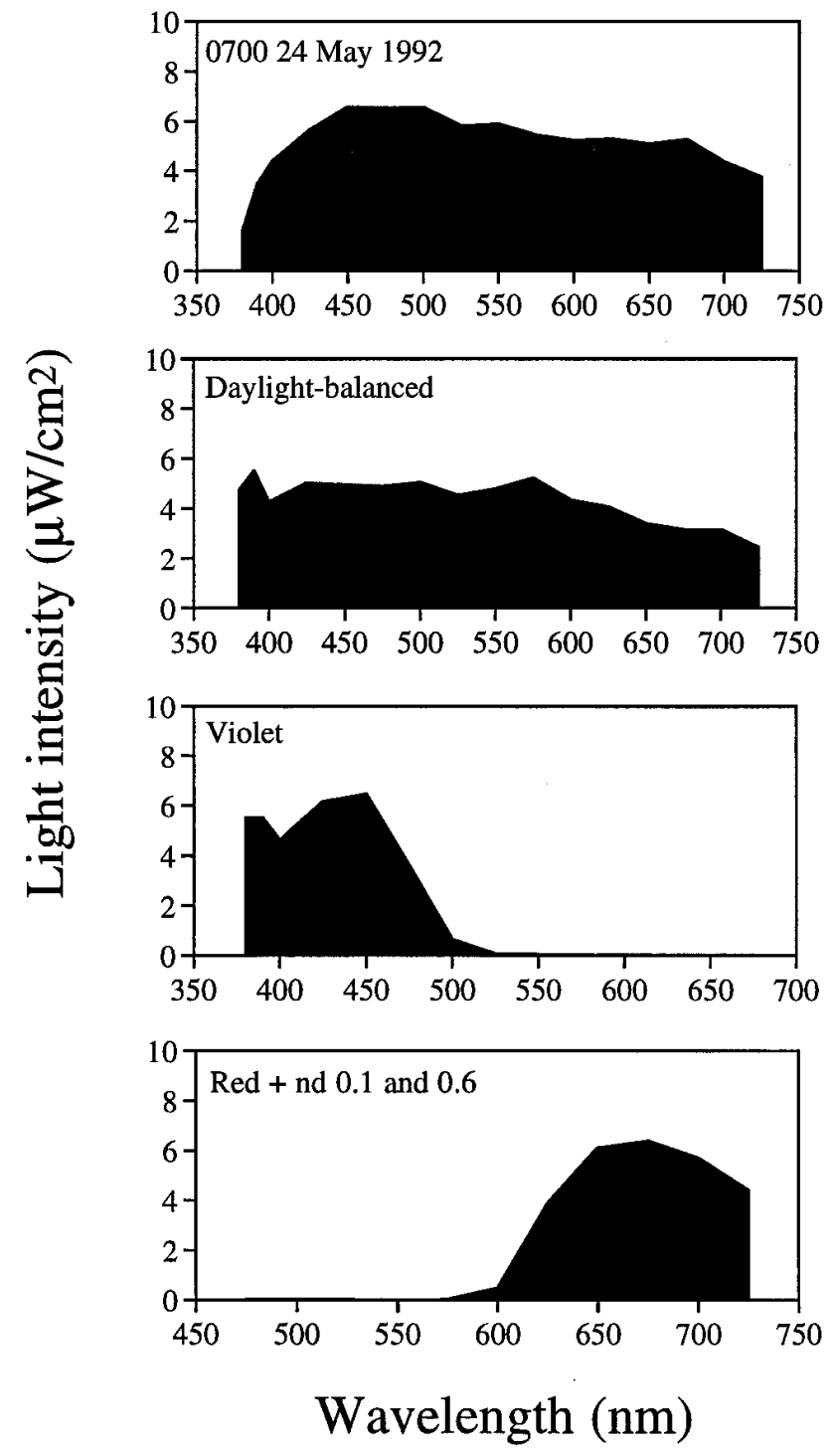

Fig. 1. Intensity and quality of light during a rain event at $0700 \mathrm{~h}$ on 24 May 1992 and that provided by various colored and neutral density (nd) filters used in studies of ascospore discharge by Venturia inaequalis in a wind tunnel during simulated rain. nd filters 0.1 and 0.6 allow 80 and $25 \%$ transmission, respectively, of light within the visible spectrum. Natural light levels were measured by a multispectral radiometer in an orchard during steady rain and are included for comparison to light levels from a 150-W halogen source measured at the sample platform of the wind tunnel. tion at $26 \mu \mathrm{W} / \mathrm{cm}^{2}$ (corresponding to intensity at $1045 \mathrm{~h}$ under above conditions) to harvest the remaining mature ascospores. The percentage of ascospores released during hours 3 to 4 was regressed against light intensity at $725 \mathrm{~nm}$ using simple linear regression. Treatments were replicated three times, and the experiment was repeated using a leaf sample from site 19 (Table 1) with the following modifications: (i) the initial dark period was $3 \mathrm{~h}$ and (ii) subsequent illumination was for $1 \mathrm{~h}$ at $0.25,1.25$ (corresponding to intensity at $0600 \mathrm{~h}$ EST under above conditions), 2.5 , or $5.2 \mu \mathrm{W} / \mathrm{cm}^{2}$. Ascospore release during the first hour of illumination at 0.25 and $1.25 \mu \mathrm{W} / \mathrm{cm}^{2}$ was also compared with the percentage of ascospores released during darkness in the control during the same interval using Student's $t$ test $(P=0.05)$. In a further refinement, the experiment was repeated using three replicated leaf samples from site 17 (Table 1), $3 \mathrm{~h}$ of simulated rain in darkness, $1 \mathrm{~h}$ of illumination at $0.5 \mu \mathrm{W} / \mathrm{cm}^{2}$ (corresponding to intensity at $0515 \mathrm{~h}$ EST under above conditions), and an additional $5 \mathrm{~h}$ of illumination at $26 \mu \mathrm{W} / \mathrm{cm}^{2}$ to harvest the remaining mature ascospores. Controls were maintained in darkness during hour 4.

Effects of preconditioning of leaf samples on ascospore release. Leaves collected at site 67 (Table 1) were moistened with distilled water to the point of pliability. Surface water was then removed by blotting with paper towels, and 1-cm disks cut from the leaves were incubated in complete darkness at $20^{\circ} \mathrm{C}$ and $90 \%$ $\mathrm{RH}$. The disks so incubated remained pliable without the presence of surface water throughout the course of the study. This preconditioning allowed the maturation and accumulation of ascospores in the samples, without opportunity for discharge. At 2- to 5-day intervals after the start of incubation, leaf samples were placed in the wind tunnel at $1600 \mathrm{~h}$, exposed to circulating air at 90 to $94 \%$ $\mathrm{RH}$ and complete darkness overnight, and then exposed to simulated rain for $3 \mathrm{~h}$ during darkness, followed by continued simulated rain and illumination for $3 \mathrm{~h}$. Data were analyzed by regressing the proportion of ascospores released during darkness against days of incubation preceding discharge. The experiment was repeated using leaf samples collected at site 17 (Table 1).

The number of asci containing morphologically mature ascospores was determined for eight leaf collections (sites 1, 17, 19, 32, 56,60 , and 68) (Table 1) by removing 20 pseudothecia from a total of 10 leaves. The leaf collections represented populations of $V$. inaequalis collected at tree phenophases ranging from green tip to bloom. The pseudothecia were crushed on microscope slides, and development of asci and ascospores was assessed at $320 \times$ as described by Gadoury et al. (12). Leaf samples from each of the above sites were also placed in the wind tunnel at $1600 \mathrm{~h}$, exposed to 90 to $94 \% \mathrm{RH}$ overnight, and subjected to $3 \mathrm{~h}$ of simulated rain in darkness followed by $3 \mathrm{~h}$ of simulated rain and light as described above. Each pair of crushed pseudothecia from 10 leaves was analyzed as a treatment replication, while wind tunnel treatments were replicated three times. The mean number of asci containing morphologically mature ascospores was regressed against the mean proportion of ascospores released during the 3-h dark interval.

Changes in the rate of ascospore release over time were investigated in two experiments. In the first, the number of ascospores discharged per minute was recorded from three replicated leaf samples from site 67 (Table 1). The leaf sample was exposed to simulated rain and daylight-balanced illumination in the wind tunnel for $2 \mathrm{~h}$ at $6^{\circ} \mathrm{C}$, followed by $4 \mathrm{~h}$ at $20^{\circ} \mathrm{C}$ to harvest the remaining matured ascospores. The rate of ascospore discharge per minute was regressed against the time elapsed since the start of wetting. In the second experiment, three replicated leaf samples from site 67 (Table 1) were exposed to simulated rain for a total of $9 \mathrm{~h}$ at $20^{\circ} \mathrm{C}$ and were illuminated either coincident with the start of wetting or beginning 2, 3, or $6 \mathrm{~h}$ later. The percentage of ascospores discharged during the first hour of illumination was regressed against the duration of the dark interval preceding illumination $(0,2,3$, or $6 \mathrm{~h})$.

Ascospore release during darkness and light in different populations of $\boldsymbol{V}$. inaequalis. A protocol was developed to compare 
the release of ascospores during darkness and light among different populations of $V$. inaequalis from leaf collections made between the green tip and petal fall phenophases of apple (Table 1). Leaf disks from each evaluated site were placed in the wind tunnel at $1600 \mathrm{~h}$ and were exposed to an air flow of 20 liters $/ \mathrm{min}$ at $20^{\circ} \mathrm{C}$ and 90 to $94 \% \mathrm{RH}$ overnight in complete darkness. At $0800 \mathrm{~h}$ the following morning, simulated rain was applied to the samples, followed by daylight-balanced illumination for $3 \mathrm{~h}\left(2.4 \mu \mathrm{W} / \mathrm{cm}^{2}\right.$ at $725 \mathrm{~nm}$ ). The RH during the simulated rain was maintained at 90 to $94 \%$. Leaf samples from each site were evaluated three times.

Field studies on ascospore release during simulated rain events. Three plots approximately $4 \mathrm{~m}^{2}$ were surrounded by wire mesh to contain apple leaves during winter in level grass fields. Severely scabbed leaves were collected beneath unsprayed 'McIntosh' apple trees at Geneva, NY, and were placed within these enclosures in autumn of each year of the study. Three to four days before bud break of the cultivar McIntosh, canopies approximately 4 $\mathrm{m}^{2}$ were suspended approximately $2 \mathrm{~m}$ above each plot to shield the enclosed leaves from rainfall. The canopy consisted of an opaque plastic tarp in 1992, while clear plastic sheeting was used in 1993 and 1994. Light intensity at the center of the covered enclosures was approximately $30 \%$ of outside levels in 1992. Light quality within the visible spectrum was not altered by the presence of the opaque canopy in 1992. Neither light intensity nor quality were affected by the clear plastic canopy used in 1993 and 1994. At the center of each enclosure, a Burkard volumetric spore sampler (Burkard Manufacturing, Ltd., Rickmansworth, Hertfordshire, England) was installed and operated to sample 12 liters of air per min. The samplers were powered by $120-\mathrm{V}$ AC motors and operated continuously throughout the study.

Ascospores collected on the clear plastic tape of the Burkard sampler were enumerated by mounting 48 -mm-long sections of the tape on microscope slides in lactoglycerol and scanning the tape at right angles to the direction of rotation at a magnification of 320 to 800 at 2-mm intervals, which corresponded to a time interval of $1 \mathrm{~h}$. The number of ascospores counted in each transect was adjusted for the magnification used, but not for trap efficiency, and cumulative ascospore release was calculated from the summation of ascospores counted in each transect.

The covered enclosures were exposed to simulated rain every 3 , 6 , or 9 days by installing a single sprinkler head at the center of each plot, which dispensed water evenly over the floor of the enclosure at the rate of $0.93 \mathrm{~cm} / \mathrm{h}$. Simulated rain treatments commenced on the day of bud break of the cultivar McIntosh in the case of the 3-day wetting-interval plot. To prevent interplot interference in trapping airborne ascospores, the 6-day and 9-day wetting-interval treatments were begun 1 and 2 days later, respectively. Thus, throughout the study, no two plots were wet on the same day. Simulated rain applications began at $2100 \mathrm{~h}$ EST and continued until $1500 \mathrm{~h}$ the following day (18 h total duration). A datalogger (model CR-10; Campbell Scientific Inc., Logan, UT) at the site provided hourly measurements of temperature and leaf wetness within the covered enclosures. Leaf wetness and temperature were measured by a single metallic grid (model 237; Campbell Scientific Inc.) or thermistor (Fenwal Electronics, Inc., Framingham, MA) sensor, respectively, mounted within the leaf litter at the center of the enclosure.

\section{RESULTS}

Effect of low RH on the suppression of ascospore release by darkness. In both populations from New York and Sweden, the use of relatively dry (10 to $15 \% \mathrm{RH})$ air in the wind tunnel resulted in a substantially greater percentage of ascospore release during darkness (Fig. 2). The effect of low RH on ascospore release during darkness was observed in the first hour of exposure to simulated rain, and subsequent wetting during darkness resulted in no significant increase (Student's $t$ test, $P=0.05$ ) in the cumulative discharge at hours 1 and 2 or 2 and 3 (Fig. 2). Ascospore release accelerated and a higher rate of release was maintained when light was supplied to the leaf samples at the end of hour 3 (Fig. 2).

Effects of light quality and intensity on ascospore release. After an initial $2 \mathrm{~h}$ of darkness and simulated rain in a wind tunnel, ascospore release from site 68 during hours 3 to 6 reached $13.2 \%$ ( standard error $[\mathrm{SE}]=1.07)$ in darkness, $13.4 \%(\mathrm{SE}=1.23)$ when exposed to violet light, $43.7 \%(\mathrm{SE}=3.59)$ when exposed to red light, and $41.6 \%(\mathrm{SE}=2.97)$ when exposed to daylight-balanced illumination. Comparable ascospore releases from sample site 17 were $8.3 \%(\mathrm{SE}=0.89), 8.9 \%(\mathrm{SE}=1.21), 21.1 \%(\mathrm{SE}=3.72)$, and $24.8 \%(\mathrm{SE}=2.66)$. Release during exposure to violet light was not significantly different from that observed in darkness $(P=0.05)$. Release during exposure to red light was not significantly different $(P=0.05)$ from that observed in daylight-balanced illumination.

Linear regression analysis indicated that the rate of ascospore discharge upon exposure to light was directly proportional to light intensity between 0.25 and $5.2 \mu \mathrm{W} / \mathrm{cm}^{2}$ (Fig. 3) in samples from sites 19 and 67 . The percentage of ascospores released during the first hour of illumination at $0.25 \mu \mathrm{W} / \mathrm{cm}^{2}$ was not significantly different from the percentage of ascospores released during darkness (Student's $t$ test, $P=0.05$ ), but was significantly greater at $1.2 \mu \mathrm{W} /$ $\mathrm{cm}^{2}$. In samples from site 17 , ascospore release during the first hour of illumination at $0.5 \mu \mathrm{W} / \mathrm{cm}^{2}$ was $9.9 \%$ ( $\mathrm{SE}=1.46$ ) compared with $1.2 \%(\mathrm{SE}=0.79)$ in darkness during the same interval.

Effects of preconditioning of leaf samples on ascospore release. Increasing the duration of incubation without opportunity for ascospore release resulted in an increasing percentage of ascospores released during darkness in wind tunnel tests (Fig. 4). In
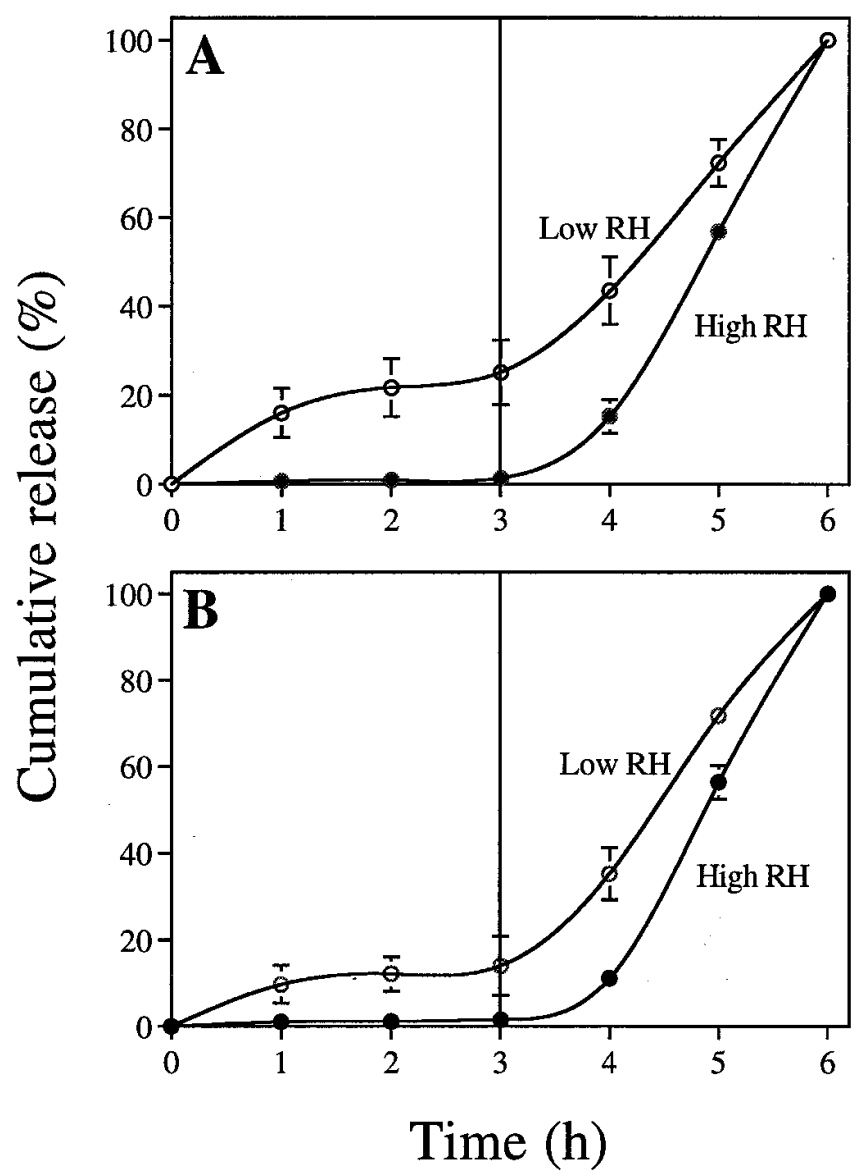

Fig. 2. Effect of low (10 to $15 \%$ ) and high (90 to $95 \%$ ) relative humidity upon release of ascospores of Venturia inaequalis in a wind tunnel during darkness and light. The left and right panels of each graph represent treatments of darkness and illumination, respectively. Leaf samples from A, Geneva, NY, or $\mathbf{B}$, Alnarp, Sweden, were exposed to simulated rain in darkness for $3 \mathrm{~h}$, followed by $3 \mathrm{~h}$ of simulated rain and light at $20^{\circ} \mathrm{C}$. Interpolated curves are fit to means of three replications for each leaf collection. 
the case of samples from site 67 , this response was immediate and linear (Fig. 4A), while the response was delayed and exponential in pseudothecia from site 19 (Fig. 4B). Furthermore, the percentage of ascospores released during darkness in eight populations was directly proportional to the percentage of asci containing morphologically mature ascospores (Fig. 5).

The rate of ascospore release increased over time at $6^{\circ} \mathrm{C}$, after an initial lag period of $30 \mathrm{~min}$ during which there was little or no ascospore release (Fig. 6). The increase in rate of discharge was nonlinear and was sustained over the 2-h duration of the $6^{\circ} \mathrm{C}$ phase of the experiment (Fig. 6). When illumination of the leaf sample was delayed after the onset of simulated rain, an increasing percentage of the ascospores was discharged during the first hour of illumination (Fig. 7).

Ascospore release during darkness and light in different populations of $\boldsymbol{V}$. inaequalis. In general, the longer the interval between bud break and collection of the leaf samples from the various sites, the higher the percentage of ascospores released during darkness. Among populations of pseudothecia borne on scabbed apple leaves collected at the green tip stage of apple fruit buds, ascospore release during a 3-h dark interval in the wind tunnel tests averaged $3.8 \%$ and ranged from 1.4 to $7.5 \%(n=10)$ (Table 1). Comparable release during darkness was $7.9 \%$ from a single population collected at $1 \mathrm{~cm}$ green, $14.8 \%$ from a single population at tight cluster, $14.9 \%$ at pink $(n=3), 62.3 \%$ at bloom $(n=3)$, and $38.6 \%(n=2)$ at petal fall (Table 1$)$.

Field studies on ascospore release during simulated rain events. The seasonal rate of ascospore maturation was not affected by the length of the interval between wetting events in any year of
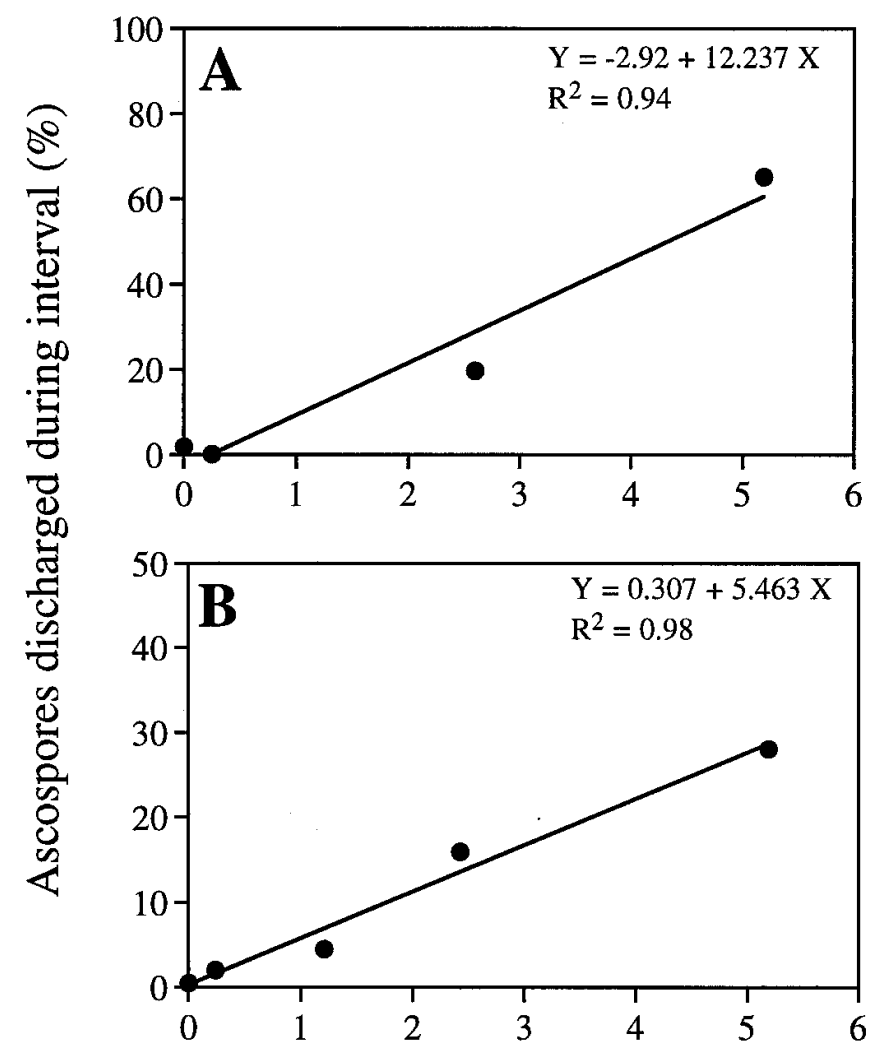

\section{Light intensity at $725 \mathrm{~nm}\left(\mu \mathrm{W} / \mathrm{cm}^{2}\right)$}

Fig. 3. Effect of light intensity on release of ascospores by Venturia inaequalis. A, Percentage of ascospores released during $2 \mathrm{~h}$ of illumination at various light intensities following $2 \mathrm{~h}$ of simulated rain and darkness. Leaf samples from Geneva, NY. B, Percentage of ascospores released during $1 \mathrm{~h}$ of illumination at various light intensities following $3 \mathrm{~h}$ of simulated rain and darkness from leaf samples from Njös, Norway. the study. The cumulative distributions of ascospore discharge were probit transformed and analyzed by linear regression. The $y$-intercepts, slope coefficients, and variances of the resultant models were not significantly different at $P=0.05$, and the data were combined for further analysis. As was noted in the wind tunnel studies above, a higher percentage of ascospores were released during the dark interval ( $2100 \mathrm{~h}$ to $0700 \mathrm{~h}$ the following day) at bloom than at green tip (Fig. 8). Lack of suppression of ascospore release during darkness was not evident until more than $80 \%$ of the season's ascosporic inoculum had been trapped (Fig. 9). Based upon the apparent change in the response to light at near-80\% cumulative ascospore maturity, the data were arbitrarily divided at into two sets: 0 to $80 \%$ and $>80 \%$ cumulative ascospore maturity. Linear regression of the percentage of ascospores discharged before $0700 \mathrm{~h}$ against the seasonal cumulative percentage of ascospore trapped from 0 to $80 \%$ yielded a model with a $y$-intercept of $3.93 \%$ and a slope coefficient not significantly different $(P=0.05)$ from 0 (Fig. 9A). Thereafter, the percentage of ascospores released during darkness increased in a nonlinear fashion until the season's inoculum was depleted (Fig. 9B). After square-root transformation to linearize the response variable, simple regression analysis yielded a model with a slope coefficient of 0.234 (Fig. 9B), which was significantly different from $0(P=0.05)$.

\section{DISCUSSION}

RH and ascospore release during darkness. Under orchard conditions, ascospore release by $V$. inaequalis occurs during rain and, to a lesser degree, during dew (30). Dew is associated with
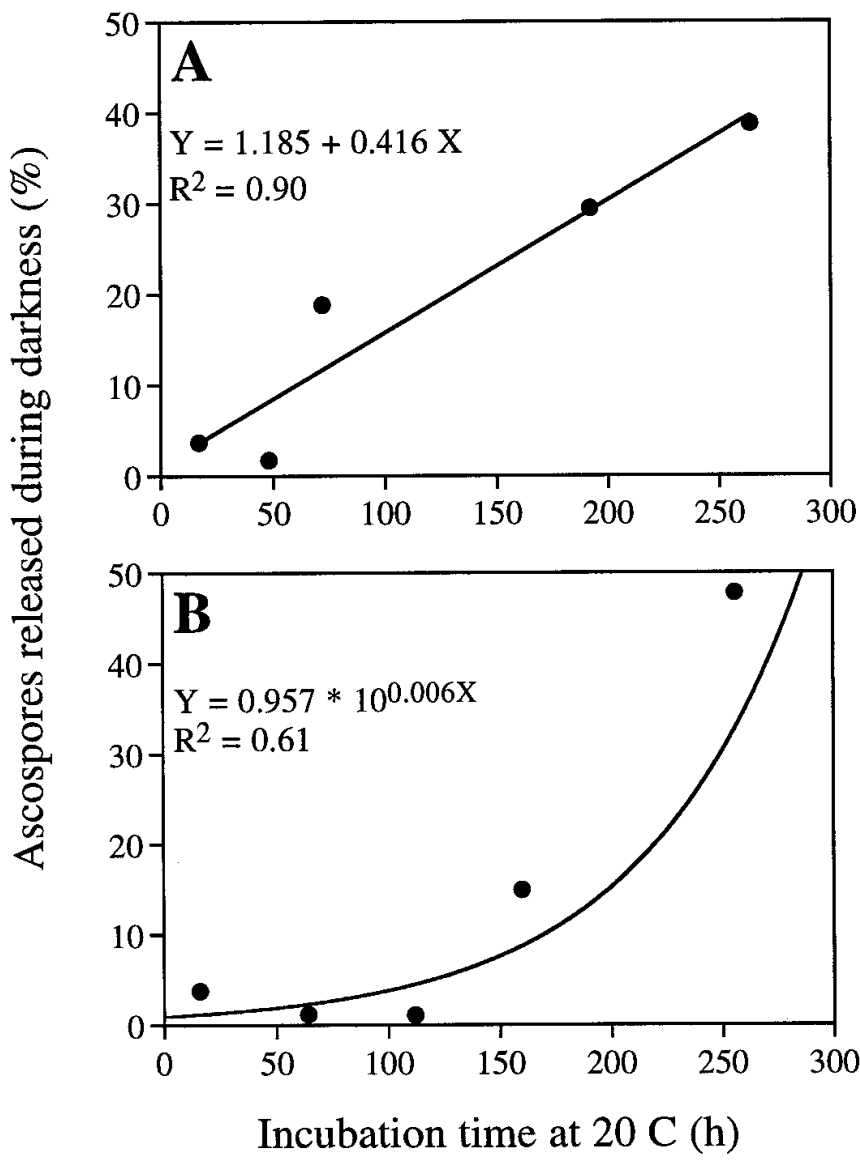

Fig. 4. Effect of incubation of leaf samples on release of ascospores during darkness by Venturia inaequalis populations from A, Geneva, NY, and $\mathbf{B}$, Njös, Norway. Leaf samples collected at bud break of apple were incubated for 17 to $264 \mathrm{~h}$ at $20^{\circ} \mathrm{C}$, and then subjected to $3 \mathrm{~h}$ of simulated rain in darkness, followed by $3 \mathrm{~h}$ of simulated rain and illumination. 
saturated atmospheres, and RH remained above $70 \%$ during all rain events at Geneva, NY, between 1992 and 1996 (D. M. Gadoury, unpublished data). Thus, when a dry air stream was passed over the leaf samples in our wind tunnel studies, it represented an unnatural environment for ascospore release, in which rainfall was coincident with very low humidity. The observed breakdown of the normal suppression of ascospore release during darkness was equally unnatural. The use of a humidified air supply resulted in a response (Fig. 2) typical of the pattern reported in several orchard studies of ascospore release during natural rain (i.e., suppression of ascospore release during darkness and stimulation during light) $(3,9,18$, $20,21,29)$. Unnaturally low RH may have been a confounding factor in the aberrant patterns of ascospore release observed in some previous laboratory and greenhouse studies $(17,33)$. To reproduce the pattern of ascospore discharge observed in orchards, laboratory assays must provide a reasonable reproduction of the salient environmental features of an orchard, hence the emphasis placed upon the development of a specialized wind tunnel for these studies (16).

Light quality, light intensity, and ascospore discharge. In two populations from widely separated geographic areas (Alnarp, Sweden, and Geneva, NY), we obtained a similar stimulation of ascospore release in response to light in the waveband from approximately 625 to $725 \mathrm{~nm}$. Wavelengths below $500 \mathrm{~nm}$ did not stimulate ascospore release, nor did the use of daylight-balanced illumination, which contained the intermediate waveband from 500 to $625 \mathrm{~nm}$, cause a stimulation of ascospore release that was significantly greater than the response to red light. Thus, the earlier ob-

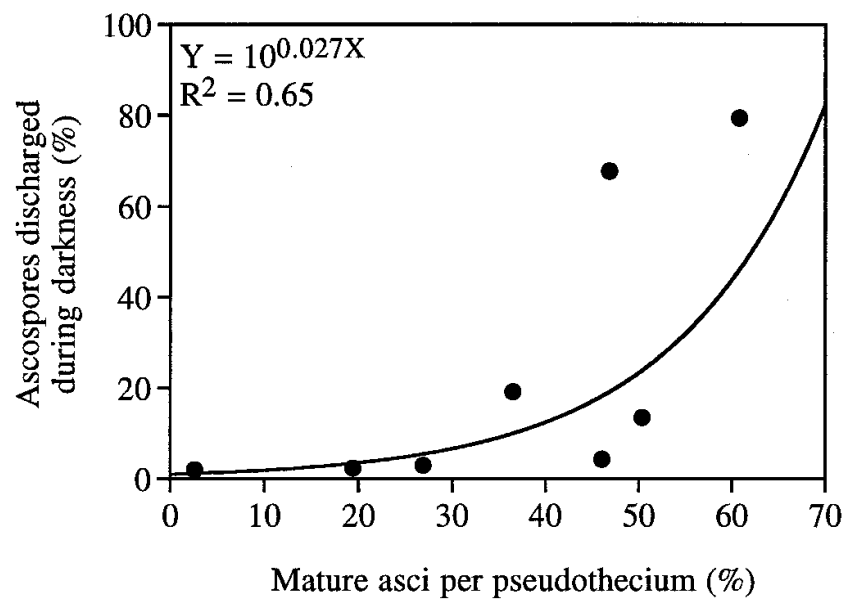

Fig. 5. Relationship between the mean percentage of asci containing mature ascospores per pseudothecium and the percentage of ascospores released during darkness in eight populations of Venturia inaequalis.

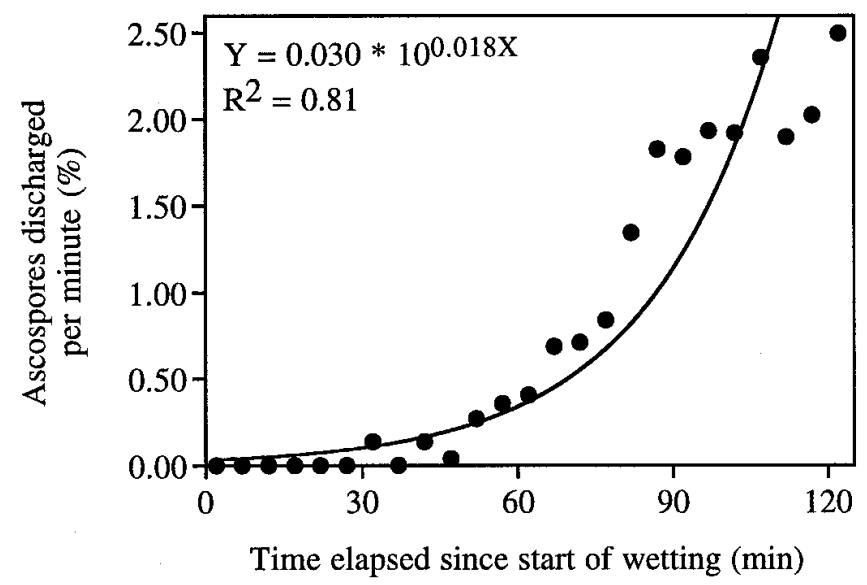

Fig. 6. Increase in the rate of ascospore release by Venturia inaequalis over time during exposure to simulated rain and daylight-balanced illumination at $6^{\circ} \mathrm{C}$ in a wind tunnel. servations of Brook $(6,7)$ in New Zealand on the effects of red light on ascospore release in $V$. inaequalis can probably be applied to other geographic regions.

Under orchard conditions, the rate of ascospore discharge increases immediately after sunrise, but the peak rate of release is not reached until nearly 3 to $6 \mathrm{~h}$ later $(19,21)$. Is this because the light intensity needed for the maximum rate is relatively high? Does the increasing intensity of light between dawn and noon $(13,16)$ cause an increasing rate of discharge? The minimum intensity of light required to stimulate ascospore release is relatively low compared with the typical intensity shortly after sunrise. For example, during the rain event on 24 May 1992 (Fig. 1), light intensity at $725 \mathrm{~nm}$ reached the threshold level we found for stimulation of ascospore release $\left(0.5 \mu \mathrm{W} / \mathrm{cm}^{2}\right)$ between 0500 and $0515 \mathrm{~h}$, but it had increased to $4 \mu \mathrm{W} / \mathrm{cm}^{2}$ by $0700 \mathrm{~h}$ and $12 \mu \mathrm{W} / \mathrm{cm}^{2}$ by $0900 \mathrm{~h}$. We did demonstrate a positive relationship between light intensity and the rate of ascospore discharge (Fig. 3). However, we also demonstrated that the rate of ascospore release increased substantially over time at a constant light intensity (Fig. 6). Thus, the delay in reaching the peak rate of ascospore release after sunrise may be due to the combined impact of increasing light intensity after sunrise and the intrinsic increase in the rate of discharge over time. The magnitude of the time-dependent increase in the rate of ascospore discharge may itself be dependent upon temperature (31), with low temperatures resulting in a delay in reaching the peak

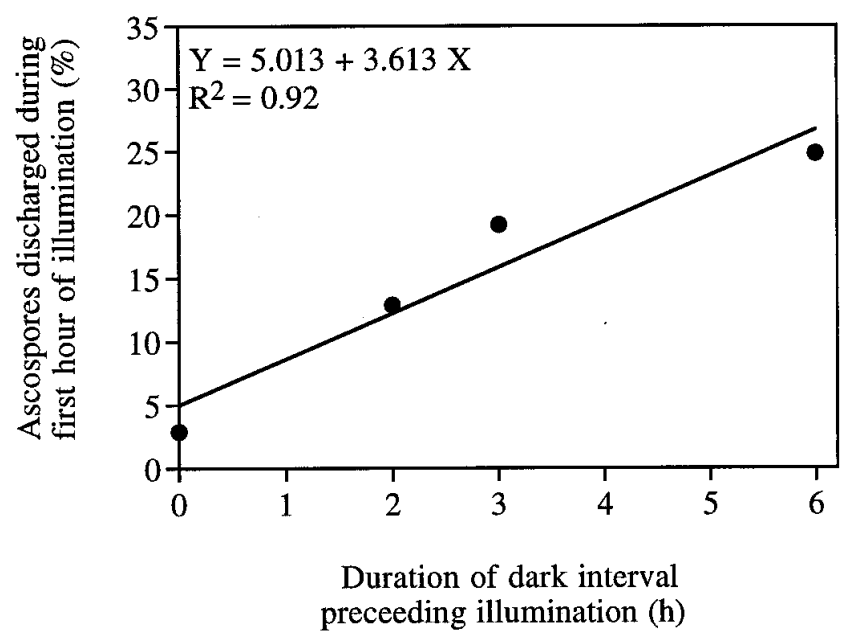

Fig. 7. Effect of wetting during darkness upon the rate of ascospore release by Venturia inaequalis upon initial illumination. Leaf samples from Geneva, NY, were exposed to simulated rain in a wind tunnel. Daylight-balanced illumination was supplied at $0,2,3$, or $6 \mathrm{~h}$ after the start of simulated rain.

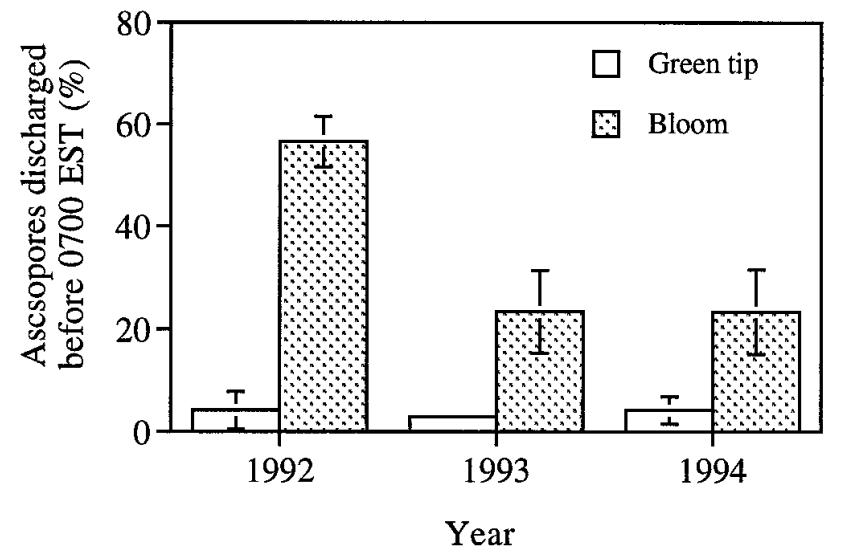

Fig. 8. Percentage of ascospores of Venturia inaequalis released prior to $0700 \mathrm{~h}$ during wetting events at the green tip and bloom stages of apple fruit buds at Geneva, NY, from 1991 to 1993. Bars indicate one standard error of mean values. 
rate of discharge. This phenomenon has also been noted in previous orchard studies $(18,21,28)$. Finally, we found that the duration of the dark interval preceding illumination can affect the rate of ascospore discharge once light is available (Fig. 7). Therefore, a more rapid response to light could be expected as the duration of wetting during darkness is increased.

Impact of preconditioning of leaf samples and maturity of populations on ascospore discharge. Several lines of evidence suggest that the suppression of ascospore release during darkness breaks down as populations of pseudothecia senesce. Incubation of leaf samples for extended periods resulted in the maturation, and perhaps senescence, of the majority of the season's total inoculum. We incubated moist leaf samples collected at green tip for up to 11 days at $20^{\circ} \mathrm{C}$. This corresponded to the accumulation of 220 degree-days (base $=0^{\circ} \mathrm{C}$ ), enough to mature 40 to $70 \%$ of the season's total ascospore supply (10), in addition to what had matured in the samples prior to incubation. With each successive day of incubation, a larger percentage of the total ascospore discharge occurred during darkness in the wind tunnel (Fig. 4). In wind tunnel tests, cumulative ascospore releases during darkness in excess of $10 \%$ (Table 1) were associated with the presence of pseudothecia containing higher numbers of mature asci (Fig. 5). Populations with higher numbers of mature asci were collected at later phenological stages of apple (Table 1), which are associated with the depletion of the ascospore supply (20). While this trend was possibly exaggerated in the international collection because of maturation of pseudothecia during shipment of leaf samples to Geneva,
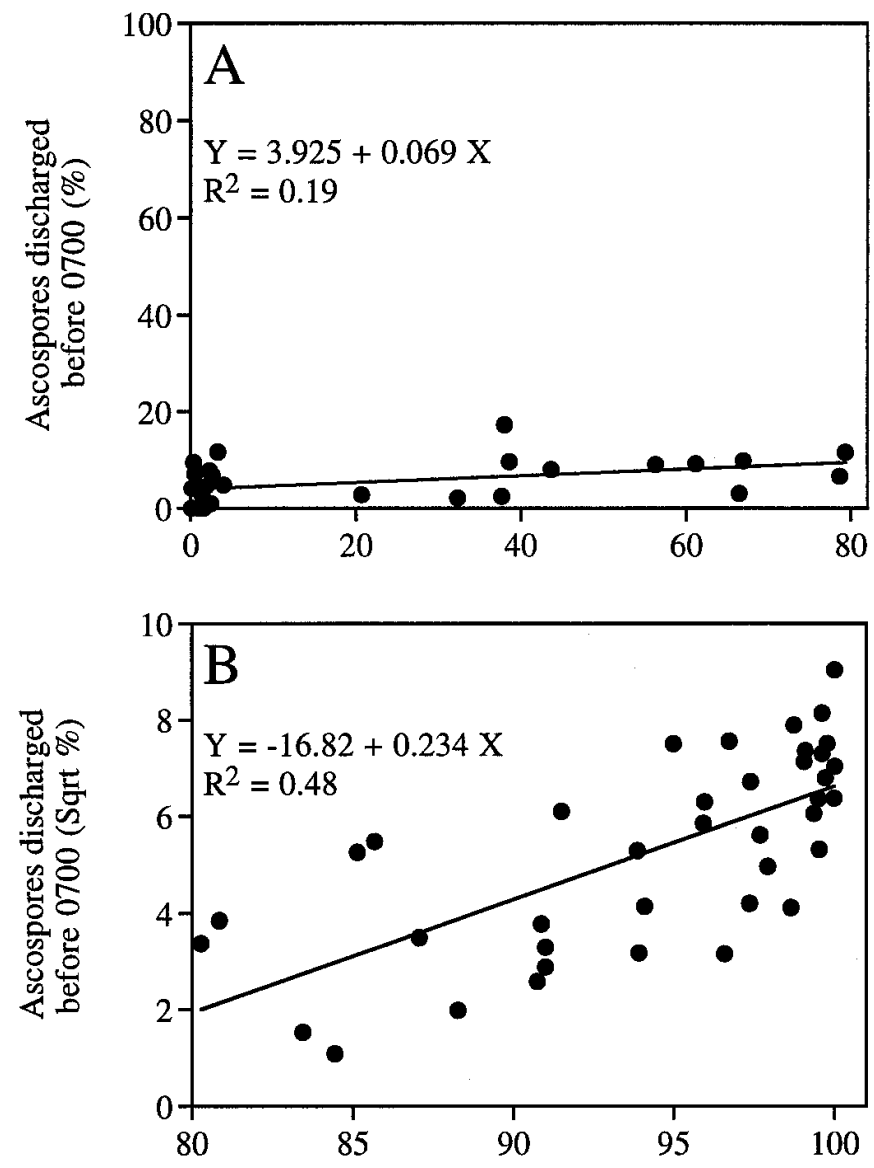

Cumulative ascospore release (\%)

Fig. 9. Effect of maturation and senescence on the suppression of ascospore release by Venturia inaequalis during darkness. The percentage of ascospores released before $0700 \mathrm{~h}$ during wetting events in 1992 to 1994 was regressed against the cumulative percentage of the season's total ascospores trapped at the time of the wetting events during periods A, 0 to $80 \%$ cumulative discharge and $\mathbf{B}, 80$ to $100 \%$ cumulative discharge. the association of elevated ascospore releases during darkness with later phenological stages was nonetheless consistent. In all 3 years of our field study, a substantially higher percentage of ascospores were discharged during darkness at bloom than at green tip (Fig. 8).

Loss of the suppressive effects of darkness on ascospore discharge did not appear to be a continuous or linear response until near the end of the ascospore maturation process in our field experiments. Once $80 \%$ or more of the ascospores matured, the potential existed for an increasing percentage of the available ascospores to be released during darkness (Fig. 9). The potential increased rapidly once $80 \%$ of the ascospores had been trapped, but the response occurred as the absolute inoculum dose was rapidly shrinking (i.e., as the last $20 \%$ of the ascospores were discharged) (Fig. 9). However, while there was a clear relationship between our experimental creation of a senescent population and elevated ascospore release during darkness in a wind tunnel and during simulated rain in the field, no such phenomenon was reported in previous extensive studies of ascospore release during continuous or discontinuous natural rain events in New Hampshire (21), Geneva and Highland, NY (14), and North Carolina (3).

Practical impact of results on recommendations for management of apple scab. The earliest studies of ascospore release demonstrated that infection from ascospores occurs primarily after rain $(9,18,32,34)$. Ascospores have also been trapped in orchard air during fair weather $(18,21,24)$ and following dew $(26,30)$, but release during fair weather or following dew has never been shown to result in detectable infections. Mills (25) provided the first practical means to use basic information on rainfall and ascospore discharge to time fungicide applications to control apple scab. Based upon the research of Brook (4-7), apple growers in New Zealand began in the 1970 s to ignore infection periods initiated by night rains, if the wetting interval after dawn alone was not sufficiently long to allow infection. MacHardy and Gadoury (22) suggested similar modifications to Mills' criteria to account for the suppression of ascospore release during darkness. Warner and Braun (33) proposed an extension of the daytime interval used by MacHardy and Gadoury based upon ascospore release observed in eastern Canada. It is important to note that all prior discussions of the patterns of ascospore release in $V$. inaequalis have largely involved percentages and proportions, and that the threat posed by ascosporic inoculum is determined by airborne ascospore dose. The numerous revisions to Mills' criteria with regard to day and night release of ascospores are only appropriate for use in commercial orchards where potential ascospore dose (11) is relatively low. Many commercial orchards harbor relatively small populations of $V$. inaequalis as compared with research orchards (11). The percentage of available ascospores released by night rains is generally a small part of the potential release $(3,5-7,21)$. The important question in regard to control of apple scab is whether or not 5 to $10 \%$ of the maximum airborne ascospore dose in a well-managed commercial orchard represents a threat to the crop. MacHardy and Gadoury (22) provided an estimate of the maximum airborne ascospore dose that is likely to occur in a well-managed commercial orchard at night. Further evidence of the low risk of infection at low airborne ascospore doses was provided in a 6-year study by MacHardy et al. (23), in which trees in low-inoculum commercial orchards were not sprayed for one to five infection periods, without regard to timing of the wetting events and without significant increases in fruit infection. Where the potential ascospore dose is relatively high, severe fruit infection could result from ascospores released during the night. Based on this work (23), a potential ascospore dose of 1,000 ascospores per $\mathrm{m}^{2}$ was recommended as a threshold level of inoculum below which infection periods could be ignored during early host growth. This threshold level of potential ascospore dose could also be used conservatively now to identify orchards where timing of rain can be used to refine forecasts of infection. Until the potential of late-season breakdown of the suppression of ascospore release during darkness can be more clearly defined, we would also 
suggest that elevated levels of ascospore release during night-time rain events should be considered a possibility once $90 \%$ of the ascospore population has matured, an event approximately coincident with the accumulation of 400 degree-days (base $=0^{\circ} \mathrm{C}$ ) after bud break (10). In very dry weather, during which substantial degreeday accumulation could occur, but during which the rate of ascospore maturation might be retarded (20), the petal-fall stage of fruit bud development could be substituted for the above suggested degree-day threshold.

\section{LITERATURE CITED}

1. Aderhold, R. 1896. Die Fusicladien unserer Obstbäume. Teil I. Landw. Jahrb. 25:875-914.

2. Aylor, D. E., and Anagnostakis, S. L. 1991. Active discharge distance of Venturia inaequalis ascospores. Phytopathology 81:548-551.

3. Aylor, D. E., and Sutton, T. B. 1992. Release of Venturia inaequalis ascospores during unsteady rain: relationship to spore transport and deposition. Phytopathology 82:532-540.

4. Brook, P. J. 1966. The ascospore production season of Venturia inaequalis (Cke.) Wint., the apple black spot fungus. N.Z. J. Agric. Res. 9:1064-1069.

5. Brook, P. J. 1969. Effect of light, temperature, and moisture on release of ascospores by Venturia inaequalis (Cke.) Wint. N.Z. J. Agric. Res. 12: 214-227.

6. Brook, P. J. 1969. Stimulation of ascospore release in Venturia inaequalis by far red light. Nature 222:390-392.

7. Brook, P. J. 1975. Effect of light on ascospore discharge by five fungi with bitunicate asci. New Phytol. 74:85-92.

8. Darpoux, H., Lebrun, A., and de la Tullaye, B. 1975. Action de traitements sur la formation des peritheces et la production de l'inoculum primaire de Venturia inaequalis (Cooke) Wint. et de Venturia pirina Adher. Phytiatr. Phytopharm. Rev. Fr. Med. Pharm. Veg. 24:3-14.

9. Frey, C. N., and Keitt, G. W. 1925. Studies of spore dissemination of Venturia inaequalis (Cke.) Wint. in relation to seasonal development of apple scab. J. Agric. Res. 30:529-540.

10. Gadoury, D. M., and MacHardy, W. E. 1982. A model to estimate the maturity of ascospores of Venturia inaequalis. Phytopathology 72: 901-904

11. Gadoury, D. M., and MacHardy, W. E. 1986. Forecasting ascospore dose of Venturia inaequalis in commercial apple orchards. Phytopathology 76:112-118.

12. Gadoury, D. M., Seem, R. C., Rosenberger, D. A., Wilcox, W. F., MacHardy, W. E., and Berkett, L. P. 1992. Disparity between morphological maturity of ascospores and physiological maturity of asci in Venturia inaequalis. Plant Dis. 76:277-282.

13. Gadoury, D. M., Seem, R. C., and Stensvand, A. 1994. Ascospore discharge in Venturia inaequalis. Norw. J. Agric. Sci. Suppl. 17:205-219.

14. Gadoury, D. M., Seem, R. C., and Stensvand, A. 1995. New developments in forecasting the risk of apple scab. N.Y. Fruit Q. 2:5-8

15. Gadoury, D. M., Stensvand, A., and Seem, R. C. 1992. Effects of tem- perature, humidity, and preconditioning on ascospore discharge in Venturia inaequalis. (Abstr.) Phytopathology 82:1105.

16. Gadoury, D. M., Stensvand, A., and Seem, R. C. 1996. A wind tunnel for controlled-environment studies of ascospore release by Venturia inaequalis. Phytopathology 86:596-601.

17. Gjærum, H. B. 1954. Ascospore maturity, dissemination and infection by apple scab. Norw. Plant Prot. Inst. Bull. 13.

18. Hirst, J. M., and Stedman, O. J. 1962. The epidemiology of apple scab (Venturia inaequalis (Cke.) Wint.). II. Observations on the liberation of ascospores. Ann. Appl. Biol. 50:525-550.

19. Knoppien, P., and Vlasveld, P. N. 1947. Vier Jaren Voortgezet Onderzoek over de Schurft van Appel en Peer. Tijdschr. Plantenziekten 53:147-172.

20. MacHardy, W. E. 1995. Apple Scab: Biology, Epidemiology, and Management. The American Phytopathological Society, St. Paul, MN.

21. MacHardy, W. E., and Gadoury, D. M. 1986. Patterns of ascospore discharge by Venturia inaequalis. Phytopathology 76:985-990.

22. MacHardy, W. E., and Gadoury, D. M. 1989. A revision of Mills's criteria for predicting apple scab infection periods. Phytopathology 79:304-310.

23. MacHardy, W. E., Gadoury, D. M., and Rosenberger, D. A. 1993. Delaying the onset of fungicide programs for control of apple scab in orchards with low potential ascospore dose of Venturia inaequalis. Plant Dis. 77:372-375.

24. Miller, P. M., and Waggoner, P. E. 1958. Dissemination of Venturia inaequalis ascospores. Phytopathology 48:416-419.

25. Mills, W. D. 1944. Efficient use of sulfur dusts and sprays during rain to control apple scab. Cornell Ext. Bull. 630.

26. Moore, M. H. 1958. The release of ascospores of apple scab by dew. Plant Pathol. 7:4-5.

27. Palm, G. 1988. Untersuchungen über den Einflu $\beta$ der Belichtungsstärke für den Askosporenaussto $\beta$ des Schorfpilzes (Venturia inaequalis, Venturia pirina). Mitt. Biol. Bundesanst. Land Forstwirtsch. 245:420.

28. Seem, R. C., Gilpatrick, J. D., and Szkolnik, M. 1981. Quantitative effects of microclimate on spore development and dispersal systems of apple scab. Pages 135-137 in: Proc. Symp. Int. Cong. Plant Prot., IX. Burgess Publishing Co., Minneapolis, MN.

29. Stensvand, A., Amundsen, T., and Semb, L. 1993. Apple scab (Venturia inaequalis)—Patterns of ascospore release in Norway. Norw. J. Agric. Sci. Suppl. 17:49-54.

30. Stensvand, A., Amundsen, T., Semb, L., Gadoury, D. M., and Seem, R. C. 1998. Discharge and dissemination of ascospores by Venturia inaequalis during dew. Plant Dis. 82:761-764.

31. Stensvand, A., Gadoury, D. M., Amundsen, T., Semb, L., and Seem, R. C. 1997. Ascospore release and infection of apple leaves by conidia and ascospores of Venturia inaequalis at low temperatures. Phytopathology 87:1046-1053

32. Wallace, E. 1913. Scab disease of apples. N.Y. Agric. Exp. Stn. Bull. 335.

33. Warner, J., and Braun, P. G. 1992. Discharge of Venturia inaequalis ascospores during daytime and nighttime wetting periods in Ontario and Nova Scotia. Can. J. Plant Pathol. 14:315-321.

34. Wiesmann, R. 1932. Untersuchungen über die Überwinterung des Apfelschorfpilzes Fusicladium dendriticum (Wallr.) Fckl. im totenBlatt sowie die Ausbreitung der Sommersporen (Konidien) des Apfelschorfpilzes. Landwirtsch. Jahrb. Schweiz 36:620-679. 